\title{
RELIEF OF LIGHTNING PAINS IN TABES DORSALIS
}

\author{
BY \\ W. FOWLER \\ Assistant to the Department for Venereal Diseases, The General Infirmary, Leeds
}

The immediate relief of lightning pains in tabetics remains a problem. Though sedatives are still the commonest drugs prescribed, medical measures such as administration of vitamin $B_{1}$, ephedrine, adrenaline, and insulin have been suggested on supposed ætiological grounds, but have failed to meet with general approval. Surgical procedures, such as epidural injections, division of the nerve roots, and cordotomy, have also been tried with varying degrees of success. One year ago, it was thought that lightning pain might be relieved by anæsthetizing the skin area where the pain was felt, in the same way as the referred shoulder-tip pain in perforated peptic ulcer can be abolished by infiltrating the skin over the shoulder-tip with procaine hydrochloride. In 1936 Alajouanine and others, working on the assumption that lightning pains were due to peripheral stimuli, claimed that after 10 to $20 \mathrm{c.cm}$. of 2 per cent. procaine hydrochloride were infiltrated into "trigger zones" in the skin, the pains disappeared.

\section{Report on Eight Tabetic Patients}

The following is a report on eight tabetic patients who suffered from paroxysms of lightning pains, treated by infiltrating the affected skin areas with local anæsthetic. The patients complained of pain in the following situations : (1) on the dorsum of the right foot; (2) in the right heel ; (3) over the centre of both tibia anteriorly ; (4) commencing in the middle third of both thighs posteriorly and shooting down the limbs; (5) the girdle, at the level of the epigastrium ; (6) around the right side of the chest in the mid-dorsal region ; (7) multiple over the middle third of the outer aspect of the left foot; (8) commencing in both inguinal regions and shooting down the thighs.

In each case, the paroxysms lasted between two and seven days and appeared at intervals of three to seven weeks.

\section{AnAesthesia}

At first 2 per cent. " novocain" was used, 2 to $4 \mathrm{c.cm}$. being required. Later it was found that an oily solution gave better results, and therefore " proctocaine" was substituted, 1 to $2 \mathrm{c.cm}$. being used. The following technique was adopted :

(a) Where the pain struck at a fixed point, as in Cases 2 and 3, the area of skin involved was infiltrated with anæsthetic.

(b) Where the pain travelled from a constant point, as in Cases 4 and 8, the skin was infiltrated as close as possible to that point.

(c) In the case of girdle pain it was found that satisfactory results were obtained by infiltrating the skin across the path of the pain on both sides of the trunk.

(d) Where the pains were diffuse on the foot, as in Cases 1 and 7, the affected area was blocked by infiltrating around the ankle as far as was necessary.

\section{Results}

Both " novocain" and " proctocaine" gave immediate and dramatic relief from the paroxysm. Following "novocain" injection the pain returned after one to four hours ; with " proctocaine," however, it was relieved for at least two to four days. In five of the cases one injection of " proctocaine " abolished the paroxysm, while in three cases two injections were required, in one case after two days and in the other two cases after four days.

In seven of the patients, in addition to the immediate relief experienced, the interval between paroxysms has lengthened and the severity of the paroxysms has diminished. In one instance, Case 5, the paroxysms, although relieved by the anæsthetic, have not diminished in their severity or frequency of recurrence.

This method of treatment has the following advantages : (1) it is easily performed ; (2) the 
patient is immediately relieved; (3) he does not need sedatives; (4) he can carry on his work.

\section{Summary}

A method of relieving the lightning pains of tabes dorsalis by local anæsthesia is described, whereby the patient can be kept free from pain and at work until cure is effected by antisyphilitic treatment.

I am indebted to Dr. Robert Lees for his interest and help.

\section{REFERENCE}

Alajouanine T., Thurel, R., Brunelli, A. (1936). Rev. Neurol., 65, 60.

\section{BOOK REVIEW}

\section{THE GIRLS THEY LEFT BEHIND}

\section{By Grethe Hartmann}

(Ejnar Munksgaard, Copenhagen. 1946. Pp. 207. 26 tables and graphs. Price D.cr. 12-English price 15s.)

Psychological studies in prostitution, such as those of Flexner and of Kemp, were made at a time when the chief instrument of investigation was the intelligence test, and their conclusion that prostitutes were drawn from the lower grade mentalities is now familiar. Recently further studies have been undertaken, using the newer methods of psychopathology and aimed not at the investigation of the hardened prostitute but at evaluation of the personality trends in what Glover calls the " larval prostitute." This book, in spite of its faintly ridiculous title, is another contribution to such studies, and the subject matter consists of girls and women who were found to be sex contacts of German troops during their occupation of Denmark in the recent war. The author emphasizes that in most cases the women concerned were not of the hardened prostitute type, and in fact are better described as " half prostitutes."

The difficulty which faces the non-psychiatrist in making an appreciation of all these studies is chiefly that of avoiding the suspicion that, in such a highly subjective technique as psychiatric investigation, the research workers are not infrequently led into finding what they set out to find ; in other words reading into their results the hypotheses with which they started. It is, for example, a frequently expressed conclusion nowadays that " the broken home" is of prime impor- tance in causing juvenile delinquency, sexual maladjustment, divorce, and the pursuit of multiple, often entirely casual, sexual relations which is often called sexual promiscuity. Does " the broken home" or marked parental discord, however, inevitably lead to these abnormal behaviour patterns? If not, what factor or factors are responsible for the discrepancy? Does it not too often seem that the alleged and fashionably pilloried sins of the parents are used by the young and those interested in the young as a convenient and facile excuse for absence of self-discipline? Or does all the ingenuity of the psychiatrist serve but to reiterate in modern jargon the old refrain "there's no place like home"?

Altogether Dr. Hartmann investigated the behaviour patterns and family backgrounds of two hundred and twenty seven girls, and the detailed case histories take up about three-fifths of the book. Dealing with the incidence of venereal disease amongst the general population of Denmark, the author gives some interesting figures of the relatively enormous rise in venereal disease incidence during and after the German occupation. Some graphs are also given showing comparisons between Denmark and Sweden, which latter country of course was not occupied by Germany. In both countries there was a rise in the incidence of gonorrhoa and syphilis-much greater, however, in Denmark - and in both countries the increase in the incidence of syphilis was much greater proportionally than that of gonorrhœa.

This book is a useful contribution to the relatively few epidemiological and socio-psychological studies of the venereal diseases. F.R.C. 